\title{
A WIDENING GAP IN ECONOMIC CRISIS AND OPPORTUNITIES: A PERSPECTIVE OF MIGRATION AND HIV FROM DADELDHURA, FAR-WEST OF NEPAL
}

\author{
Jha CK \\ School of Behavioural, Cognitive and Social Science \\ University of New England, Armidale, NSW, Australia
}

\begin{abstract}
Introduction: A cross-sectional study was undertaken to explore socio-economic conditions of inhabitants from Dadeldhura district in Far-West Nepal.

Methodology: The study examined chances of migration to India for earning, and then possible risks of HIV transmission in migrants.

Results: It was found that most of the respondents have insufficient food supplies, which led to a large number of economically productive populations to migrate India for earning. Although the level of knowledge on HIVIAIDS was high in the respondents, they also had several confusions. The cultural restrictions forbid them to talk about the issues related to sexuality or to acquire relevant information.

Conclusion: As an implication, they remained unaware of the threat of HIV transmission despite the fact that some of them engaged in unsafe sexual behaviours. Provisions of information through peer networks seem to be effective to promote safer sexual behaviors in migrant populations.
\end{abstract}

Key words: Nepal, Poverty, Migration, HIV, Awareness

\section{INTRODUCTION}

Various studies around the world have shown that migrant workers are at increased risk of HIV transmission..$^{1-5}$ Globally, 120 million people move from country to country or within their own country every year. Another 38 million migrants constitute the internal displaced people and refugees. ${ }^{3}$

Migration in both forms, internal and external is common in $\mathrm{Nepal}^{6}$ and it is higher in Far-Western Region than any other parts of the country. ${ }^{7-10}$ A total of 658337 Nepalese migrated to different countries during a period of 1981 to 1991 of which,

\section{Correspondence:}

Chandra Kant Jha, Ph D

Honorary Associate,

School of Behavioural, Cognitive and Social Science University of New England, Armidale, NSW, Australia.

E-mail: chandrajha@hotmail.com
$68 \%$ migrated to different parts of India ${ }^{11}$, and this figure is estimated to be reached to one million. People from both countries can cross the borders freely, because there is no any legal requirement for them to have a visa. There is a long tradition of migration between Nepal and India. Cultural and religious similarities have influenced a large number of Nepalese to migrate India. ${ }^{12}$

A significant proportion of Nepalese migrants who worked in India have been detected with $\mathrm{HIV}^{13}$, as they had had unsafe sex with brothel-based sex workers in India. A brothel-based survey conducted in Mumbai, India revealed that $50 \%$ sex workers were infected with HIV. ${ }^{9}$ In recent years, migration has been fuelled in the Far-Western districts of Nepal due to ongoing political conflicts. ${ }^{14}$ The objective of this study was to identify circumstances that lead to migrate the inhabitants of Dadeldhura to India and then identify their vulnerability to HIV transmission. 


\section{METHODOLOGY}

The socio-economic factors were analysed to assess the level of the migration. Then, knowledge on HIVIAIDS and sexual behaviours of the migrant workers were explored. Altogether, 200 respondents were recruited randomly by using lottery methods from the record of households, which were prepared by the office of village development committees (VDCs). Six VDCs were included in this study of which four VDCs were in hilly regions, and two VDCs were from plain areas. There are three VDCs in plain areas, which cover half of the district's total populations. There are 20 VDCs and 1 municipality in the district. The household owners were targeted to interview, because of the fact that they would be able to provide the details about the members who migrated to India, and also how they manage family financially. A large proportion of the household owners were the male members $(191 / 200)$ who were interviewed. Interestingly, most of them had their lived experiences of ever migrated to India.

The data collectors were recruited from local communities who were educated from higher secondary to university levels, and had some experiences in data collection with other organizations. Trainings were provided to them before commencing data collection. The respondents participated in the study voluntarily after reading the information sheet, which detailed the study. Their informed consents were obtained as they decided to participate in the study. Respondents privacy and confidentiality were strictly maintained, as all the questionnaires which included their personal information, were marked by codes. All the relevant issues, importance of this research and manner in which the research was conducted, were discussed with the District AIDS Coordination Committee, which is the top level authority on HIVIAIDS in the district. All collected data were entered into EPI INFO software and were analysed.

RESULTS

Socio-economic and demographic characteristics
The study included 200 respondents of which 191 were male and 9 were female. Mean age of the respondents were 31.27 years with standard deviations (S.D.) 9.5 years. By caste groups, 105 respondents were Chhetri, 54 Brahmin, 39 Sudra and 2 were Baisya. A large majority of the respondents 175/200 were married and rests were unmarried. By educational status, 145/200 respondents were literate ranging from just able to read and write to higher secondary and above, whereas, 55/200 respondents were illiterate. A large number of the respondents $145 / 200$ were engaged in agricultural works, and others worked as labourers and owning small businesses, and of these, two respondents were students who engaged in seasonal migration too. Most of the respondents 109/200 belonged to joint families and rests had nuclear families. The mean numbers of household members were 7.85 and S.D. 3.67. Interestingly, the mean numbers of economically productive members who supported family with an income were 2.74, and S.D. 1.6.

The land ownership by the household was varied. For example, slightly more than three-fourth $(n=158)$ households owned 20 ropanil or less land, $15 \%(n=30)$ had up to 40 ropanis of land. Only 6 respondents had 41 to 80 ropani lands. One ropani land is equivalent to 508.74 square meters. The types of land vary from barren to fertile. Major foods cultivated were paddy, maize, wheat, mustard and millet. Slightly more than half of the households $(n=106)$ found these cultivated foodstuffs in their land were just sufficient for three months. Only $9 \%(n=18)$ households out of 200 were able to satisfy their food supply throughout the year. On average, their food supplies were sufficient up to 4.06 months with S.D. 3.33 .

Included all sources, income in Nepalese currency was less than $15000^{\mathrm{II}}$ rupees for $20 \%$ of households. Rest of the households had above 15000 of income, ranging from 16000 to 30000 rupees by $36.5 \%$ households, 31000 to 45000 rupees by $27 \%$ households, and rest of the households had above 45000 rupees. The

\footnotetext{
I 1 ropani land $=508.74$ square meters

II 1 US\$=70.60 Nepalese rupees
} 
primary sources of these incomes were agriculture, migration, business and a small proportion of the respondents had varied occupations. Most of the households spend their major proportion (94.5\%) of incomes on essential commodities, such as foods and clothes. The second priority is celebration of festivals by $4 \%$ of households, whereas, medication and education of siblings appear to be the least prioritized areas for their expenditures. A little over three-fourth $(76.5 \%)$ households in this study face much difficulty to cope with their family expenses. For example, $41.5 \%$ households take loan to fulfill their essential needs, such as foods and clothes, and $35 \%$ households rely on daily wage labour for which most of the families send their members to India for earning.

\section{Migration to India}

Fifty-five percents respondents (110/200) had experiences of ever being on migration to India where they stayed for 4.5 mean years and 3 years SD. Ninety-nine percents of these respondents who were migrated to India earned from rupees 500 to 4000 per month. Nearly $90 \%$ (97/110) of respondents spent their earning on food supplies for their family. This supports the fact that fulfillment of food supplies for the families is a compelling reason for migrating to India. The findings suggest that $95 \%$ people migrate to India from October to December. The major destination for the respondents were Delhi (35/110), Punjab (32/110), Mumbay (25/110) and other cities in small numbers. A large proportion (35.5\%) of 110 migrant workers engaged in factory work, whereas, other majority $(31.8 \%)$ worked as gatekeepers, and the remaining migrants were classified as hotel workers, porters, transport workers, and agricultural workers.

\section{Knowledge and risk behaviours associated to HIVIAIDS}

A large proportion (87.3\%) of the respondents (96/110), who gave a history of being on migration, had heard of HIVIAIDS. Nearly $46 \%$ of the respondents (44/96) revealed that radio was the popular source for them to acquire information on HIVIAIDS, followed by $28.1 \%$ respondents (27/96) who claimed that they received information from their friends. Other sources stated by a small number of respondents were magazine, teacher, hording board/poster, and television. Approximately fifty-eight percents (55/96) of the respondents perceived AIDS as a fatal disease and nearly $38 \%$ respondents conceptualized that AIDS is a disease which is transmitted due to having unsafe sex. A small proportion of the respondents perceived AIDS equal to STD, and some revealed that it is transmitted through casual contacts. The level of awareness regarding the modes of HIV transmission was varied among respondents. For example, a little over 59\% respondents (65/110) mentioned four correct ways of HIV transmission, whereas, $24.5 \%$ and $12.73 \%$ respondents stated three and two correct ways of HIV transmission respectively. To protect oneself from HIV transmission, approximately two-thirds of the respondents $(71 / 100)$ stated that one should have sex only with their husband or wife, whereas nearly $17 \%$ (18/110) respondents revealed that condom should be used while having sex with other than the spouse. Other small proportions of the respondents said that sharing of needles $(7.27 \%)$, and transfusion of unchecked blood (by 3.64\% respondents) should be avoided. Although these findings suggest a high level of knowledge among respondents, it is also true that many respondents have confusions regarding the knowledge about HIVIAIDS. For instance, 36.4\% (40/110), 37.3\% (41/110), $40.9 \%$ (45/110), $53.6 \%$ (59/110) and $41.8 \%$ (46/110) respondents believe that HIV can be transmitted through handshake, hugging, sharing clothes, mosquito bites and sharing toilets respectively while these questions were asked separately. These beliefs were common even in the respondents who were educated to some extent. While exploring the advantages of condom usage, approximately $93 \%$ (88/95) respondents stated that condom is useful to protect from HIV transmission through sexual intercourse. Other advantages of condom use as revealed by a small proportion of respondents were birth spacing and protection from STDs.

While trying to examine condom use and premarital and extramarital sexual relationships, $41.5 \%$ (27/65) respondents had sex with other than their spouses and nearly $31 \%(20 / 65)$ used condoms. 
Overall, the condom use was claimed by $63.1 \%$ (41/65) respondents, whereas, other $36.9 \%$ (24/65) respondents never used a condom. However, the responses given by a small number of respondents suggest that only 4 respondents out of 24 used condom correctly. Those who did not use condoms stated that they were shy to ask for the condoms (9/12) and other responses were being unaware of the condoms, condoms not available, and condom makes sex unpleasant. Most of the male migrant workers had sex with female sex workers which ranged from 1 to 12 . The sexual partners for female respondents were army/police, transport workers and male migrant workers.

\section{DISCUSSION}

The findings suggest that most of the households do not have secured food supplies for longer duration or at least for one year. Having no opportunities or means for earning in their hometown or district, many inhabitants are obliged to migrate India. While being distant from spouses and family members, some migrant workers seem to be having unsafe sex with prostitutes which place them at the risk of acquiring HIV and STDs, and then these infections are passed to their spouses and sexual partners. This finding is consistent with other study. ${ }^{7}$

The level of knowledge regarding HIV transmission and protection seem to be high, which may be as a result of ongoing HIVIAIDS intervention in the district and preventive messages disseminated through local medias. However, confusion exists among the respondents. It is also apparent that many respondents do not feel comfortable to discuss issues associated with sexual behaviours due to social stigma and taboos. As a result, their questions and confusions remain unanswered.

A feasible approach would be to disseminate information to potential migrants as to how to avoid HIV transmission, and places where to seek information and services. A peer education network would be effective to disseminate messages as per the personal needs of the migrant. They usually migrate India in their group. Furthermore, educational materials and devices such as condom should be provided at the immigration points. Also it is crucial that the organizations, which work for the minimization of HIV transmission in migrant populations should network with existing agencies, that work at the place of destinations (in India). These organizations will be a major support to seek information and services at the place of destinations. Advocacy by the local organizations and civil society would be cornerstone to attract political response on the issue of migrants' health.

\section{ACKNOWLEDGEMENTS}

The author is thankful to DDC/HMG Dadeldhura \& HIVI AIDS Programme for supporting this research. Thanks also to Dr. T.N. Jha, the former Director of NCASC, Mahesh Sharma and Prasant Adhikari from UNDP/HMG HIVIAIDS Programme for their inputs.

\section{REFERENCES}

1. Maticka-Tyndale E, Elkins D, Haswell-Elkins M, Rujkarakorn D, Kuyyakanond T, Stam K. Contexts and patterns of men's commercial sexual partnerships in northeastern Thailand: implications for AIDS prevention. Soc Sci Med 1997;44:199213.

2. Smith-Estelle A, Gruskin S. Vulnerability to HIV/ STIs among rural women from migrant communities in Nepal: a health and human rights framework. Reprod Health Matters 2003;11:142-151.

3. UNAIDS. Migration and HIVIAIDS. 1998.

4. Bredell H, Williamson C, Sonnenberg P, Martin DJ, Morris L. Genetic characterization of HIV type 1 from migrant workers in three South African gold mines. AIDS Res Hum Retroviruses 1998;14:677684.

5. Fitzgerald K, Chakraborty J, Shah T, Khuder S, Duggan J. HIVIAIDS knowledge among female migrant farm workers in the midwest. J Immigr Health 2003;5:29-36.

6. Dignan T, Haynes KE, Conway D, Shrestha NR: Land and landlessness among rural-to-rural migrants in Nepal's Terai region. Int Reg Sci Rev 1989;12:189-209.

7. Shakya G. Situational study of the migrant workers of Mid and Far-West Nepal for evaluation of STD, HIV and AIDS infection. J Nepal Med Assoc 1997;35:130-9. 
8. New ERA. HIVISTI prevalence and risk factors among male migrant and non-migrants in Kailali district. New ERA 2002:2.

9. Reinfeld MR. Nepal: a cultural prostitution. Child World 1993;20:45-6.

10. Bott SR, Shah $I H$, Jejeebhoy S. Cross-cutting issues in social science research. WHO 1998:5968 .
11. http:// www.mope.gov.np/population/demographic. php. Nepal Population Report 2002

12. Pokharel B, Aryal S, Bhattarai A, Pyakuryal A, Subedi B. Situation Analysis of HIVIAIDS in Nepal. Richoi Associates 2000:1-64.

13. Gurung A. Nepal: a potentially explosive situation. Child World 1993;20-4.

14. Martinez E. conflict related displacement Nepal. 2002:26. 